\title{
Determination of the seismicity and peak ground acceleration for Lombok island: an evaluation on tectonic setting
}

\author{
Didi S. Agustawijaya ${ }^{1,{ }^{*}}$, Heri Sulistiyono ${ }^{1}$, and Ikhwan Elhuda ${ }^{1,2}$ \\ ${ }^{1}$ Post-Graduate Study Program in Civil Engineering, University of Mataram, Mataram 83125, \\ Indonesia \\ ${ }^{2}$ Ministry of Energy and Mineral Resources, West Nusatenggara, Mataram 83125, Indonesia
}

\begin{abstract}
Lombok Island is located in the Nusatenggara region, which is considered as one of the most active seismic parts of Indonesia. The determination of seismicity is crucial to the island, since Lombok Island is a relatively dense populated small island. Earthquakes that occurred around the island were generated by southern subduction mega-thrust and northern back-arc thrust. Mostly, distributions are concentrated on the north-west and south-east parts of Lombok Island. Probabilistic data analysis of 309 earthquake events during the period of 1973 - 2017 results in the Gutenberg-Richter parameters ( $a$ and $b$ ) of 3.62 and-0.53 indicating medium to high seismic activities. The Joyner-Boore attenuation relation seems to be suitable for seismic characteristics of the island. The reconstruction of tectonic setting indicates that the Benioff zone may develop at the depths of $150 \mathrm{~km}$ beneath the island causing horizontal tectonic forces working within the direction of $\mathrm{N} 171^{\circ} \mathrm{E}-\mathrm{N} 351^{\circ} \mathrm{E}$. This could create a strike-slip fault on the crustal basement within the NE - SW direction.
\end{abstract}

\section{Introduction}

Lombok Island is located in the Nusatenggara region, which is one of the most active seismic parts in Indonesia. The island is tectonically located in the west of the Sunda Arc where the Australian Continental Plate subducts beneath the Eurasian Plate [1, 2], (Fig. 1).

Earthquake events around the island were generated by two seismic sources: southern subduction mega-thrust and northern back-arc thrust. These two sources fashioned different types of seismic events. The subduction tends to generate deep events; conversely the backarc thrust tends to generate shallow seismic events.

In terms of seismic events, the $a$ - and $b$-values of the Gutenberg-Richter relation indicate the intensity and seismicity of the region being investigated [3]. These seismic parameters may be determined from the Gutenberg-Richter distribution graph showing the $b$-value of the linear slope of the N cumulative number - magnitude, and the $a$-value of the slope line crossing the $\mathrm{N}$ cumulative number axis [3]. Based on the graph, the $b$-value could

*Corresponding author: didiagustawijaya@unram.ac.id 
be approaching 1, but it varies depending on many processes [4], such as fault heterogeneity [5]. In another way, the $b$-value may be determined by utilizing probabilistic approaches [6].

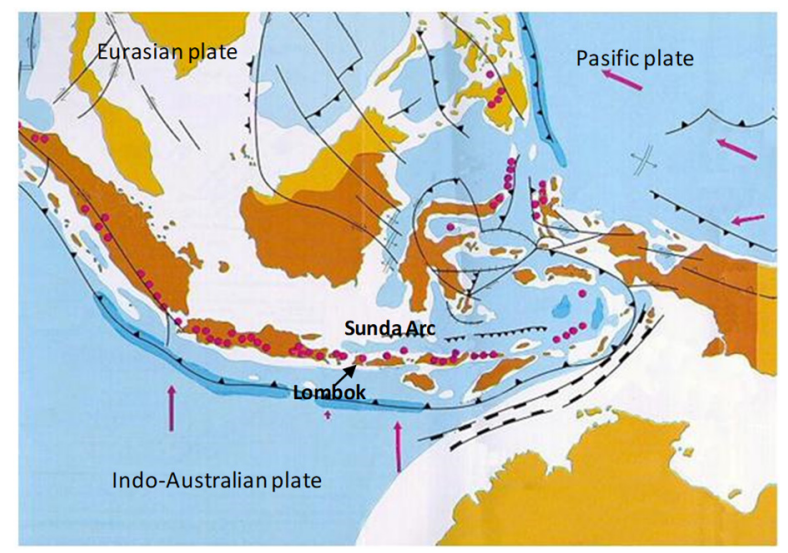

Fig. 1. Tectonic pattern of Indonesia [1, 2].

In seismic events, seismic energy is transferred from a fault surface to a recording instrument, for which a strong motion is recorded. The seismic energy from a point to the following point reaches some peak velocity, then slows to a stop, so that each point accelerates on the surface. Based on data collected, empirical equations may be employed [7]. However, the peak ground acceleration may depend on typical sources of earthquakes around the area. For the case of Lombok Island, it is crucial to evaluate the seismicity and calculating peak ground acceleration, as they could provide high impact to the island, since it is a densely populated small island [8]. The tectonic setting of Lombok Island is, therefore, reconstructed.

\section{Method}

Earthquake catalogues used in the study were derived from the Indonesian Geophysics and Climatology Agency (BMKG) and the United State Geological Survey (USGS) during the period of $1973-2017$. The centre point of investigation is the geographical coordinate (longitude and latitude) of 116.324944 and -8.650979 within a radius of $150 \mathrm{~km}$ of Lombok Island. Earthquake records were of magnitudes over 3.0 and at depths of $\leq 400 \mathrm{~km}$.

To determine seismicity of Lombok Island, the Gutenberg-Richter relationship was followed [3]:

$$
\log N_{(M)}=a-b M
$$

where $\mathrm{N}_{(\mathrm{M})}$ is the number of earthquakes with magnitude greater than or equal to M. The $a$ value is a seismic intensity parameter depending on the number of earthquake events. The $b$-value is a seismicity parameter determined as the linear slope on the graph of the $\mathrm{N}_{(\mathrm{M})}$ number and magnitude $\mathrm{M}$. The $b$-value can also be determined by utilising the maximum likelihood method $[4,6]$ :

$$
b=\frac{\log e}{M_{\text {ave }}-M_{0}}
$$

$\mathrm{M}_{\mathrm{ave}}$ is the average magnitude, and $\mathrm{M}_{\mathrm{o}}$ is the minimum magnitude. 
Three attenuation empirical relations of Esteva-Villaverde [9], McGuire [10], and Joyner-Boore [11] were applied to calculate peak ground acceleration (PGA). These three empirical relations may have different characteristics in use depending on typical earthquake patterns of the location being investigated [12]. As Lombok Island is influenced by three patterns of earthquakes: deep megathrust, deep Benioff and shallow back-arc thrust, three attenuation models could be applied, which may show a suitable pattern for Lombok Island, as follows:

The Esteva-Villaverde attenuation model is one of the earliest models applied for shallow patterns:

$$
P G A=5600 * \operatorname{EXP}(0.6 M s) *(R+40)^{2}
$$

PGA in $\mathrm{cm} / \mathrm{sec}^{2}$

$\mathrm{M}_{\mathrm{S}}=$ surface magnitude

$\mathrm{R}=$ hypocentre distance

The McGuire attenuation model could be suitable for moderate to deep patterns:

$$
P G A=472.3 * 10^{0.278 M s} *(R+25)^{-1.301}
$$

PGA in gal

$\mathrm{M}_{\mathrm{S}}=$ surface magnitude

$\mathrm{R}=\left(\mathrm{r}^{2}+\mathrm{H}^{2}\right)^{0.5}$

$\mathrm{r}=$ epicentre distance

$\mathrm{H}=$ depth

The Joyner-Boore may be suitable for moderate to shallow patterns:

$$
P G A=10^{[0.71+0.23(M-6)-\log (r)-0.0027(r)]}
$$

PGA in $\mathrm{g}$

$\mathrm{r}=\left(\mathrm{R}^{2}+8^{2}\right)^{0.5}$

$\mathrm{R}=$ hypocentre distance

The PGA data obtained from the three attenuation models were, therefore, plotted on the geological structure map of Lombok Island to reconstruct the tectonic setting of the Island.

\section{Results and discussion}

\subsection{Earthquake distribution}

Earthquake data show that at least 309 earthquakes occurred during the period of 19732017 distributed around Lombok Island (Fig. 2). When geographical coordinates of Lombok Island are put on the centre point within a radius of $150 \mathrm{~km}$, earthquakes seem to occur mostly at the north-west and north-east sides of the island (Fig. 3). Similar distribution tendencies were also indicated for Sumbawa Island [13]. 


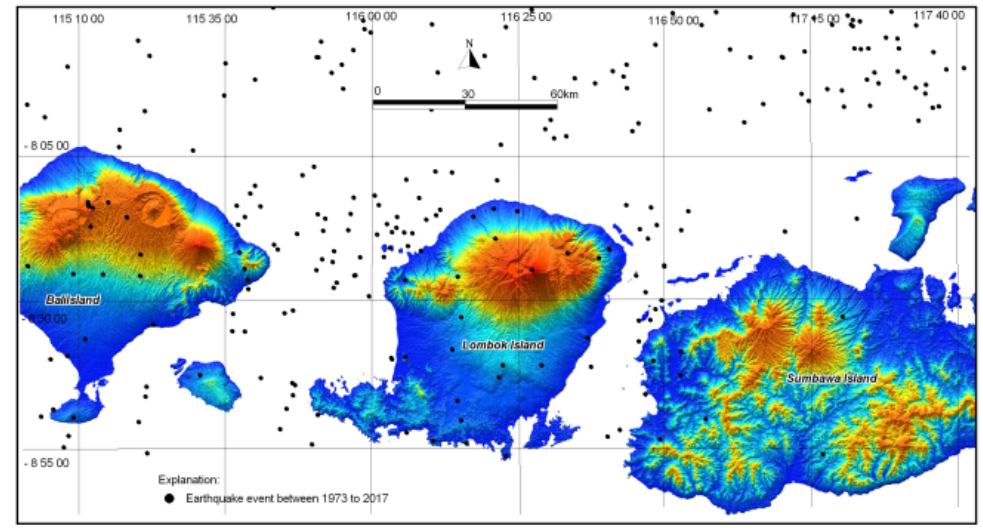

Fig. 2. Distribution of earthquakes during the period of $1973-2017$.

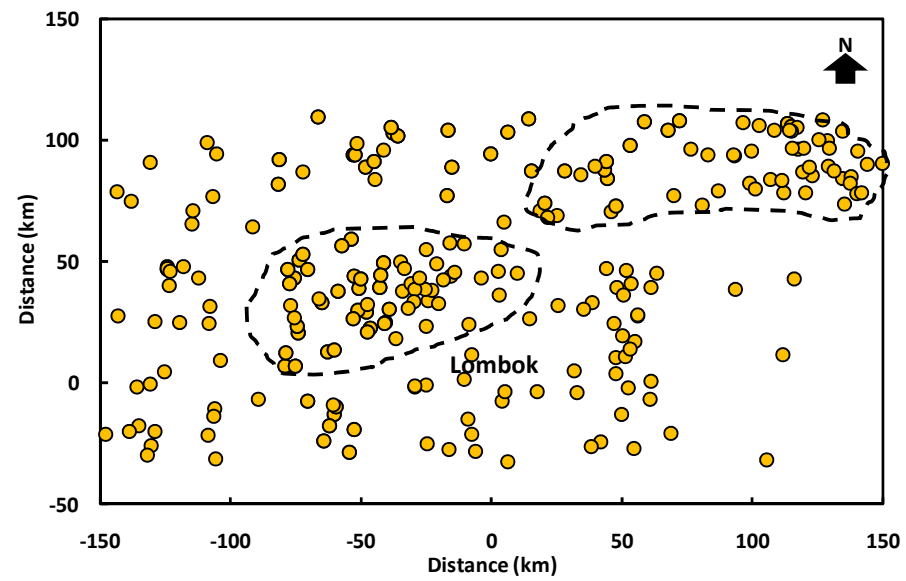

Fig. 3. Distribution of earthquakes around Lombok Island within a radius of $150 \mathrm{~km}$ within the period of 1973-2017.

These earthquake events had magnitudes of over 3.0 Richter scale (RC) at depths of $\leq$ $400 \mathrm{~km}$, but most of them had magnitudes of over $4.0 \mathrm{RS}$ (Fig. 4). The highest event was $6.3 \mathrm{RS}$ at a depth of $33 \mathrm{~km}$ occurring at a distance of $29 \mathrm{~km}$ at the north-west of Lombok Island. 


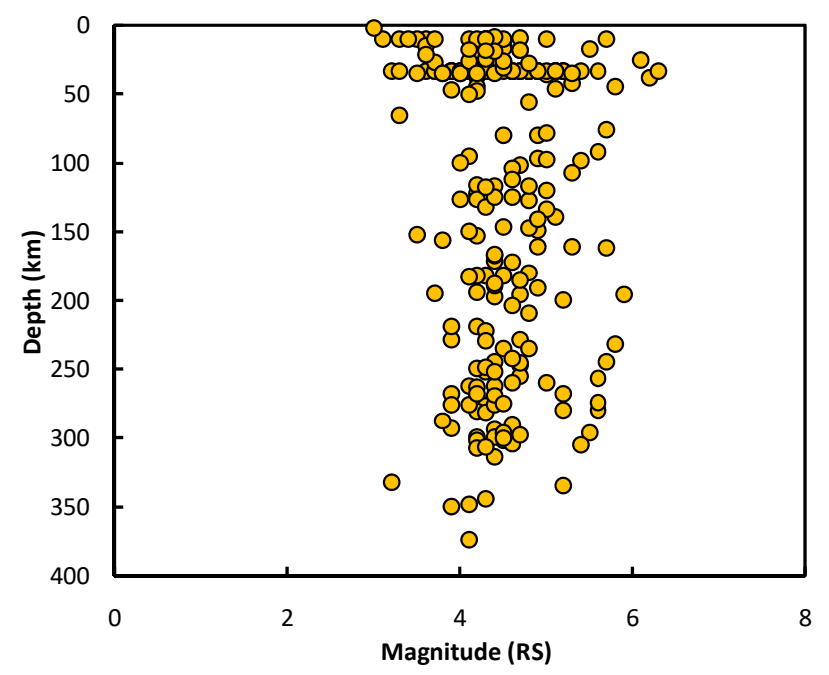

Fig. 4. Magnitude vs depth of earthquakes around Lombok Island in the period of 1973-2017.

\subsection{Seismicity}

Earthquake distribution data are plotted in Fig. 5. Probabilistic data analysis for magnitudes equal or over 4.0 RS shows that the least square method results in $a$-and $b$-values of 3.62 and -0.53 , while the maximum likelihood method results in a $b$-value of -0.66 . Those values indicate medium to high categories of seismic events [4].

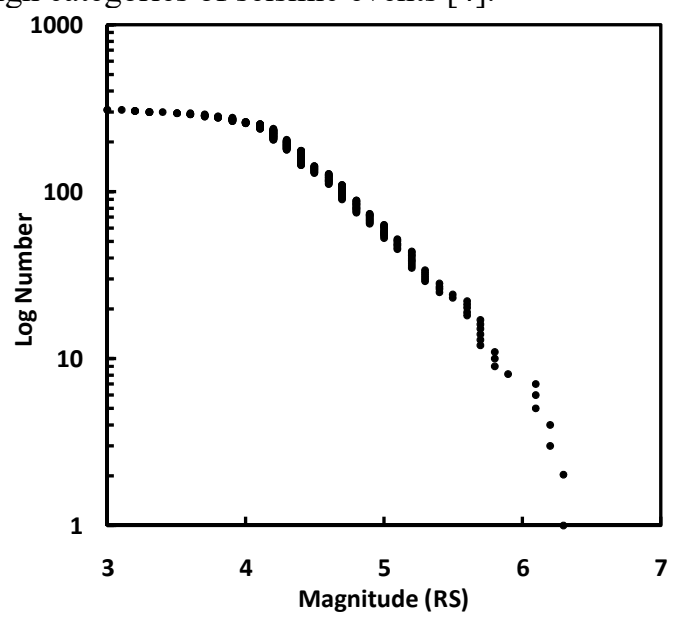

Fig. 5. Earthquake data distribution of the Gutenberg-Richter relation.

However, seismicity varies depending on many processes, such as fault heterogeneity [14] and the stress level imposed on rocks that depend on micro fracturing [15]. An area with a low $b$-value has a relatively low potential for a big earthquake compared to an area with a high $b$-value. This is called temporal variations in $b$-values [16], and their relations to the forthcoming damaging earthquakes have been discussed by many authors $[16,17]$. Many cases show that the $b$-value decreases before large earthquakes and the decrease even occurred for several years before large earthquakes occur [17]. 


\subsection{Peak ground acceleration}

Three empirical equations were utilized. The Esteva-Villaverde empirical equation produced low PGA values among three empirical equations (Fig. 6). The PGA values are between $0.003 \mathrm{~g}$ and $0.11 \mathrm{~g}$. The McGuire empirical relation shows the PGA values between $0.01 \mathrm{~g}$ and $0.72 \mathrm{~g}$; while, the Joyner-Boore empirical relation shows the PGA values between $0.003 \mathrm{~g}$ and $0.28 \mathrm{~g}$.

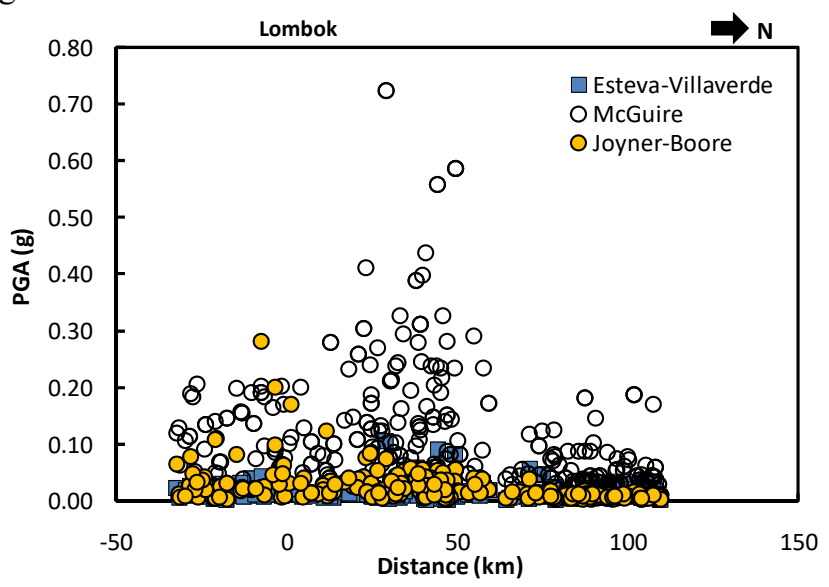

Fig. 6. Empirical PGA values for Lombok Island.

According to Hadley et al. [7], earthquake ground motions are influenced by source, propagation, and site effects. Shallow back-arc up thrust seems to be dominant in influencing seismic occurrences in Lombok Island, as it is close to the island. The Esteva-

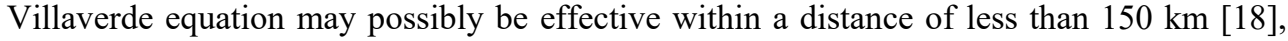
and also, the equation tends to have less deviation in value compared to the other two equations. However, as suggested by Boore [19], ground motion prediction equation should provide reasonable predictions for insufficient data, but predicts engineering-important situations; so the Joyner-Boore equation may indicate the influence of magnitude, distance, and site characterization that is suitable to Lombok Island. The PGA data of the JoynerBoore were then plotted on the map, as can be seen in Fig. 7, in which the maximum PGA data are concentrated on the south-east part of the island.

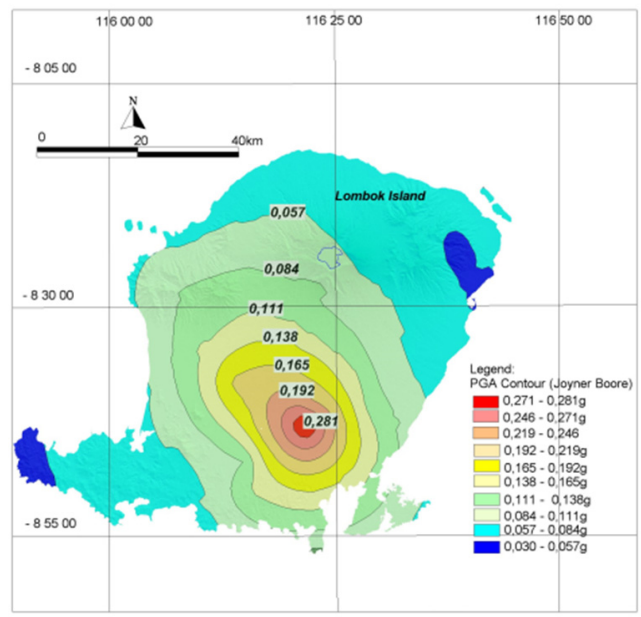

Fig. 7. PGA values estimated from the Joyner-Boore equation for Lombok Island. 


\subsection{Tectonic setting}

As discussed earlier, the tectonic pattern of Lombok Island is developed by the south subduction mega-thrust and north back-arc thrust, as a consequence of the compression between the Australian Continental Plate and the Eurasian Plate [1]. The south subduction tends to produce deep earthquakes; whereas the north back-arc thrust tends to produce shallow earthquakes (Fig. 8). The Benioff zone may develop at depths of $150 \mathrm{~km}$, similar to the so-called Benioff-Wadati zone by Rachmat et al. [2]. The zone may be inclined with an angle of $67^{\circ}$ downward north (Fig. 9).

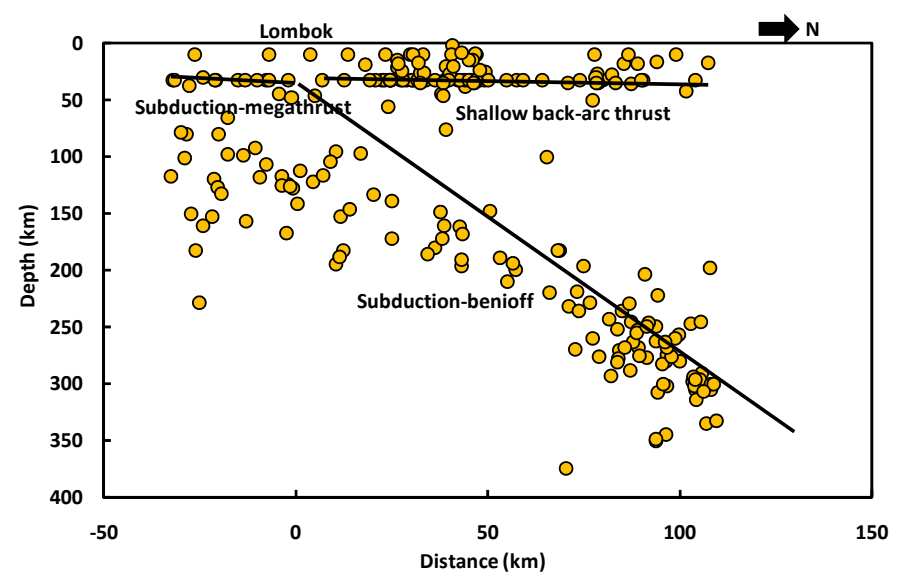

Fig. 8. Distribution of earthquake events on the tectonic setting of Lombok Island.

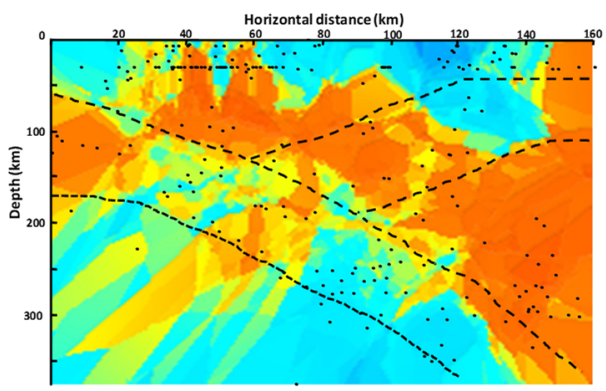

Fig. 9. Reconstructed tectonic model for Lombok Island.

Based on the geological map of Lombok [20], the island comprises of Tertiary (Early Miocene) until Holocene sedimentary rocks, and intrusive andesitic igneous rocks. The oldest rock formation is the Pengulung Formation of Late Oligocene-Early Miocene sedimentary rocks, overlaid by the Kawangan Formation of Middle Miocene sandstone. Both formations are located in the south where intrusive igneous rocks of Middle Miocene can also be found. The Ekas Formation of Late Miocene limestone overlaid the Pengulung and Kawangan Formations. In the north, young volcanic rocks dominate the geology of the island, including the Kalipalung, Kalibabak, and Lekopiko Formations.

When PGA values are plotted on the geological map, higher PGA values are concentrated on volcanic breccias of the Kalibabak and Pengulung Formations. However, there is no typical pattern between rock formations and PGA values. Thick sedimentary rock materials cover mostly parts of the island, such domination may be understandable since Mount Rinjani, located in the north, has been an active volcano in the history of 
Lombok Island [21]. The pattern seems to follow sedimentary processes of erupted materials of the Rinjani volcano.

Geological structures seem, however, to be visibly significant at the south part, as a lot of alignments are recognized in this part of the island. When the geological structure map is overlaid with the PGA map, there is a geological structure pattern that can be displayed. Structure may follow the model of Harding [22]. The geological structure of Lombok Island seems to develop on a basement sinistral strike-slip fault as the main structure in the direction of NW - SE, then minor shear strike slip faults develop in the direction of SW NE (Fig. 10). From structural patterns, a direction of main forces working at Lombok Island can be drawn on $\mathrm{N} 171^{\circ} \mathrm{E}-\mathrm{N} 351^{\circ} \mathrm{E}$. This direction is in line with the regional tectonic pattern of the Sunda Arc [1].

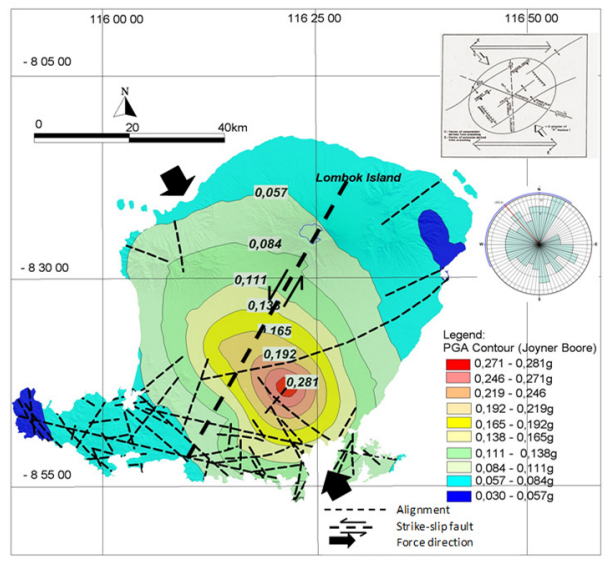

Fig. 10. Geological structure of Lombok Island.

\section{Conclusions}

Lombok Island is categorized into medium to high seismicity. The attenuation of JoynerBoore may represent ground motion of seismic event characteristics of the island, since the deep Benioff mixed with shallow back-arc thrust earthquakes dominantly occur around the island. Sinistral strike-slip fault may develop on the crustal basement in the direction of NE - SW caused by main horizontal tectonic forces working in the direction of $\mathrm{N} 171^{0} \mathrm{E}-\mathrm{N}$ $351{ }^{0} \mathrm{E}$.

\section{References}

1. W. Hamilton, Earthquake map of Indonesian region, U.S. Geo. Surv., Misc. Inv. Serial Map 1-875-C, scale 1:5.000.000, (1974).

2. H. Rachmat, M. Rosana, A. Wirakusumah, G. Jabbar, Ind. J. on Geos. 3 (2), 107-126, (2016).

3. B. Gutenberg, C. Richter, Seismicity of the Earth and Associated Phenomena, Princeton Uni. Press, New Jersey, pp. 295, (1949).

4. W. Marzocchi, L. Sandri, Annals of Geophy.,46 (6), 1271-1282, (2003).

5. K. Mogi, Bull. Earthq. Res. Inst., 40, 125-173, (1962).

6. T. Utsu, Geophy. Bull. Hokkaido Uni., 13, 99-103, (1965). 
7. D. Hadley, D. Helmberger. J. Orcutt, Bull. of the Seismol. Soc. of America, 72(3), 959-979, (1982).

8. D. Agustawijaya, Appl. Mech. \&Mat., 845, 106-110, (2016). Doi:10.4028/www.scientific.net/AMM.845.106.

9. L. Esteva, R. Villaverde, Proc. $5^{\text {th }}$ World Conference on Earthquake Engineering,2, 2586-2596, (1973).

10. R. McGuire, Earthquake Eng. Struct. Dyn., 5, 211-234. 1977

11. W. Joyner, D.Boore, Proceedings of Earthquake Engineering\& Soil Dynamics II. Geotech. Div., ASCE, 43-102, (1988).

12. J. Douglas, Ground motion prediction equations 1964-2017, Report, Dep. of Civ. and Env. Eng., Uni. of Strathclyde, Glasgow, United Kingdom, (2017).

13. B. Sunardi, M. Istikomah, Sulastri, Jur. Ris. Geof. Ind.,1(1), 23-28, (2017), (in Indonesian).

14. K. Mogi, Bull. of Earthq. Res. Inst. Uni. of Tokyo, 40, 831-883, (1962).

15. C. Scholz, Bull. of the Seism. Soc. of America, 58(3), 1117-1130, (1968).

16. Y. Shi, B. Bolt, Bull. of the Seism. Soc. of America, 72(5), 1677-1687, (1982).

17. Y. Tsukakoshi, K. Shimazaki, Earth Planets Space, 60, 915-924, (2008).

18. C. Chintanapakdee1, M. Naguit, M. Charoenyuth, The 14th World Conference on Earthquake Engineering, Beijing, China, Oct. (2008).

19. D. Boore, Ground-Motion Prediction Equations: Past, Present, and Future, The 2014 William B. Joyner Lecture, the SMIP15 meeting, Davis, California, 22 October (2015).

20. S. Mangga, S. Atmawinata, B. Hermanto, B. Setyogroho, Geological Map of The Lombok Sheet, West Nusa Tenggara, scale 1:250.000. Geol. Res. Dev. Centre, Bandung, (1994).

21. F. Lavigne, J. Degeai, J. Komorowski, S. Guillet, V. Robert, P. Lahitte, P. Wassmer, Proc. of the Nat. Aca. of Sci., 110(42), 16742-16747, (2013). DOI: 10.1073/pnas.1307520110.

22. T. Harding, J. Lowell, the Amer. Ass. of Petr. Geol. Bull., 63(7), 1016-1058, (1979). 